Article

\title{
Examining Interrelationships between Tourist Travel Mode and Trip Chain Choices Using the Nested Logit Model
}

\author{
Cong Qi ${ }^{1}$, Zhenjun Zhu ${ }^{2}$, Xiucheng Guo ${ }^{1, *}$, Ruiying Lu ${ }^{1}$ and Junlan Chen ${ }^{1}$ \\ 1 School of Transportation, Southeast University, No.2 Dongnandaxue Road, Nanjing 211189, China; \\ 220173015@seu.edu.cn (C.Q.); 220203288@seu.edu.cn (R.L.); 220183011@seu.edu.cn (J.C.) \\ 2 College of Automobile and Traffic Engineering, Nanjing Forestry University, No.159 Longpan Road, \\ Nanjing 210037, China; zhuzhenjun@njfu.edu.cn \\ * Correspondence: 101002320@seu.edu.cn
}

Received: 5 August 2020; Accepted: 11 September 2020; Published: 12 September 2020

\begin{abstract}
As tourism grows, determining methods to ease traffic problems as a result of domestic tourism holidays has become a central issue in traffic planning and management. Trip chain and travel mode choices as well as their interplays are crucial in analysing and understanding the travel behaviour of tourists, which can help to address these problems. Therefore, this study explored the relationship between destination transportation modes and trip chain choices using nested logit models wherein two nest structures were used to analyse the decision processes of travellers. Empirical analysis confirmed the effectiveness of the rational model using survey data collected from 350 respondents in Nanjing, China in 2020. The results showed that tourists preferred deciding on the trip chain prior to the travel mode, and higher time and costs were acceptable when tourists selected a complex trip chain with tour activities. Moreover, non-local tourists owning a driver's licence, travelling with companions, and staying for longer periods were more likely to use public transport with trip chains comprising tour activities; however, the relationship for trip chains with non-tour activities was the reverse. These findings are valuable for designing effective transport management strategies to ease traffic during holiday periods.
\end{abstract}

Keywords: tourism; travel behaviour; trip chain; transportation mode choice; nested logit model

\section{Introduction}

As global tourism continues to grow rapidly, the increase in tourist transport has been influenced by various factors, such as the growing number of trips per person and the increasing number of tourists from emerging countries such as Brazil, Russia, India, China, and South Africa. In China, tourism has grown rapidly, with 6.0 bn domestic tourists in 2019 compared to 3.6 bn in 2014 [1]. Rising populations (especially in urban areas) and the resulting increased demand for leisure and tourism activities have led to traffic problems in many tourist destinations. While the rapid development of long-distance transportation such as high-speed railways and airlines has promoted transport between cities and reduced traffic congestion on highways, severe traffic jams have still occurred, primarily on freeways and streets close to scenic inner cities. Most policies that have been proposed promote the tourism demand on holidays but do not relieve traffic congestion. Because of the differences in travel behaviour during weekdays and holidays, the existing policies for weekdays are not applicable during holiday periods. Therefore, it is essential to conduct research on managing tourist traffic during the holidays.

Travel behaviour research is essential to address traffic generation issues and it plays an important role in solving holiday traffic problems [2]. Among all travel behaviours, travel mode choices (such as bikes, buses, and cars) and trip chain patterns (which refer to a sequence of trips that start and end at 
home within a day) are important decisions that impact the efficiency of entire transportation systems. Thus, they have attracted considerable attention in multiple disciplines, including transportation engineering, geography, and urban economics [3]. Given the importance of domestic tourism in social development, a more comprehensive understanding of domestic tourist behaviour is needed. The objective of this study is to explore how tourists make decisions regarding their choices of travel modes and trip chains. Transportation policies could be made more effective at mitigating traffic problems during holidays through a better understanding of the travel behaviour mechanism.

Thus far, mode choices could realistically be studied within the scope of trip chains, whereas choices of travel modes and trip chains as well as their interplays have long drawn the interest of researchers. A trip chain or tour describes a sequence of trips which starts and ends at the home location. The number of activity locations included, generally referred to as the trip chain complexity, can help to divide the trip chains into simple and complex sections [4,5]. Generally, the types of trip chains in daily commuting trips can be classified into five categories, namely $\mathrm{HWH}, \mathrm{HOH}, \mathrm{HWWH}, \mathrm{HOOH}$, and $\mathrm{HWOH}$, where " $\mathrm{H}$ " denotes home, "W" denotes a work-related activity (work or school), and " $\mathrm{O}$ " refers to a non-work-related activity (maintenance, leisure, etc.) [5]. However, most research on trip chain choices focuses on daily commuting, so current research methods cannot be directly applied to analysing tourist travel behaviour. The choices of travel modes and trip chains for commuting and non-commuting tours have been studied recently $[3,6,7]$. A few studies have investigated the travel modes and trip chains chosen by tourists, indicating that the variables that significantly impact trip chains and modes are age, education, number of visits, length of stay, distance, travel time, and cost [8]. Wang et al. [2] applied the structural equation model to examine the causal effects and quantitative relationships between the influencing factors and the trip chain characteristics. Zhao [9] explored how latent factors influenced the holiday trip chain choice using the nested logit model and multinomial logit model, separately. More recent research explores destination mode choices and other travel behaviours, such as tourist departure times, travel destinations, and tourist participation; these are considered to be dependent variables in analysing the latent variable effects, where more complex discrete models such as the probit and nested logit (NL) models have been used [10-15].

On the subject of transportation mode choice, several travel behaviour studies have focused on the tourist approach, which can be divided into two main categories, including long-distance travel mode choices between the points of origin and the final tourist destinations and travel mode choices at their destinations. Several studies have been conducted on long-distance travel mode choices, which may include air, train, coach, and private car. Sociodemographic variables (such as age, income, gender, and education) and trip-related characteristics (such as length of stay, type of destinations, and time of visiting the destination) are the main variables to be considered [16-18]. Several researchers have explored the influence of travel variables such as travel distance, time, and cost on mode choices [19-21]. In terms of the destination travel mode choices, including bus, private car, taxi, and agent buses, sociodemographic and travel variables which have high frequencies have been selected as explanatory variables [22-24]. Similarly, the multinomial logit model (MNL) has been varied to analyse how these explanatory variables affect the mode choices among tourists. Several studies have utilised state preference surveys to further study the relationship between mode choices and service quality, assessed in terms of safety, convenience, and accessibility [24-27]. Sven and Bente [28] showed that the most important sociodemographic determinants in public transport use were age, household size, net household income, car availability, and current professional activity. Azari et al. [22] showed that the probability of travelling within the central business district (CBD) using public transport increased as the level of education and vehicle price increased. Le-Klahn et al. [10] found that public transport at an urban destination was more likely to be used by well-educated, first-time visitors and that travel partners also affected mode choice. Wang [29] demonstrated the influence of licence ownership, car ownership, and the number of tourist companies on the destination mode choice.

Considering the significant increases in tourist transport, existing studies have only focused on the mode choice behaviours of tourist travel; however, they have not considered or analysed the 
relationship between the trip chain and mode choices in tourist travel behaviour, where mode choices have been confirmed to be realistically within the trip chains in commuting trips. Therefore, to fill these important research gaps, this study focused on the relationship between the trip chains and travel mode choices when analysing tourist travel behaviour. Firstly, the definition of the trip chain in tourism was established: trip chains refer to a sequence of trips that start and end at a hotel or home throughout the day, involving visits to at least one destination. Specifically, two NL models for tourist travel behaviour were used to determine the order followed by tourists to make trip chain and transportation mode choices. Moreover, this study examined how the sociodemographic factors, trip-related characteristics, and travel variables influenced trip chain and destination travel mode choices. Finally, the proposed methodology was applied to analyse tourist travel in the city of Nanjing, China.

The remainder of this paper is organised as follows. Section 2 describes the data collection and descriptive statistics. Section 3 presents the modelling methodologies. Section 4 analyses the results of model estimation. Section 5 presents the discussion of results. Section 6 outlines the main conclusions.

\section{Data}

\subsection{Study Area}

The Zhongshan Mountain National Park was selected as the survey site, which consisted of Dr. Sun Yat-sen's Mausoleum, the Ming Tomb, the Linggu Scenic Area, the Meiling Palace, and the Music Stage. The scenic area was $45 \mathrm{~km}^{2}$, located in the centre of Nanjing City, one of the largest cities in Southeast China. It was rated as a National AAAAA level tourist attraction by the National Tourism Administration. The transportation infrastructure is sufficient for travellers to flexibly choose their trip modes and travel routes, as shown in Figure 1. There were more than $71.6 \mathrm{~m}$ tourists by May 2020 in Nanjing, with $36.98 \%$ of the tourists located in the Zhongshan Mountain National Park [30].

\subsection{Survey Design}

A questionnaire was specially designed to fit the objectives of this study and was divided into two main sections. The first section covered how visitors travelled to the park and the attributes of their trip chains. The second section was designed to record sociodemographic details, trip-related information, and the travel characteristics of the respondents. The data of trip chain were pre-processed by extracting the information of the number and attributes of places visited during the tour. In this study, the descriptions of trip chains were as follows, where " $\mathrm{H}$ " denotes home or hotel, " $\mathrm{T}$ " denotes a tour activity (site visit, entertainment, or leisure), and " $\mathrm{O}$ " refers to a non-tour-related activity (visiting friends or commercial activities):

- HTH: There is one tour activity during the day. This trip chain contains only a single tour-related activity stop.

- $\mathrm{HOH}$ : There is only one non-tour-related activity during the day. This chain contains only a single non-tour-related activity stop.

- HTTH: There are two tour activities during the day. This chain contains two tour-related activity stops with a mid-trip, with no non-tour-related activity stops.

- $\mathrm{HOOH}$ : There are two non-work activities during the day. This chain contains two non-tour-related stops with a mid-trip.

- HTOH: There are two types of activities during the day. This chain combines a tour-related stop and a non-tour-related stop with a mid-trip.

\subsection{Sampling and Data Collection}

In order to improve the effectiveness of the questionnaire, a polit survey was conducted by delivering the questionnaires to 30 random tourists. After receiving feedback, the final version included several changes in both content and format. Finally, questionnaires were distributed and collected 
during Tomb-Sweeping Day and International Labour Day, when people wanted to spend time outdoors in spring. The survey was used in face-to-face interviews, and respondents were randomly selected considering distributions of age and gender. Respondents were then asked if they were tourists completing their trip in one day. Questionnaires were given to qualified respondents, to be filled in and returned on the spot.

In total, 350 questionnaires were distributed, yielding 327 effective samples. However, 23 were removed from the analysis for various reasons, such as missing data and respondents being passengers in transit. Respondents who visited the Zhongshan Mountain National Park were chosen because, on the one hand, the total number of tourists there ranked first, and on the other hand, it is a representative scenic type in China and could be selected as a basic reference.

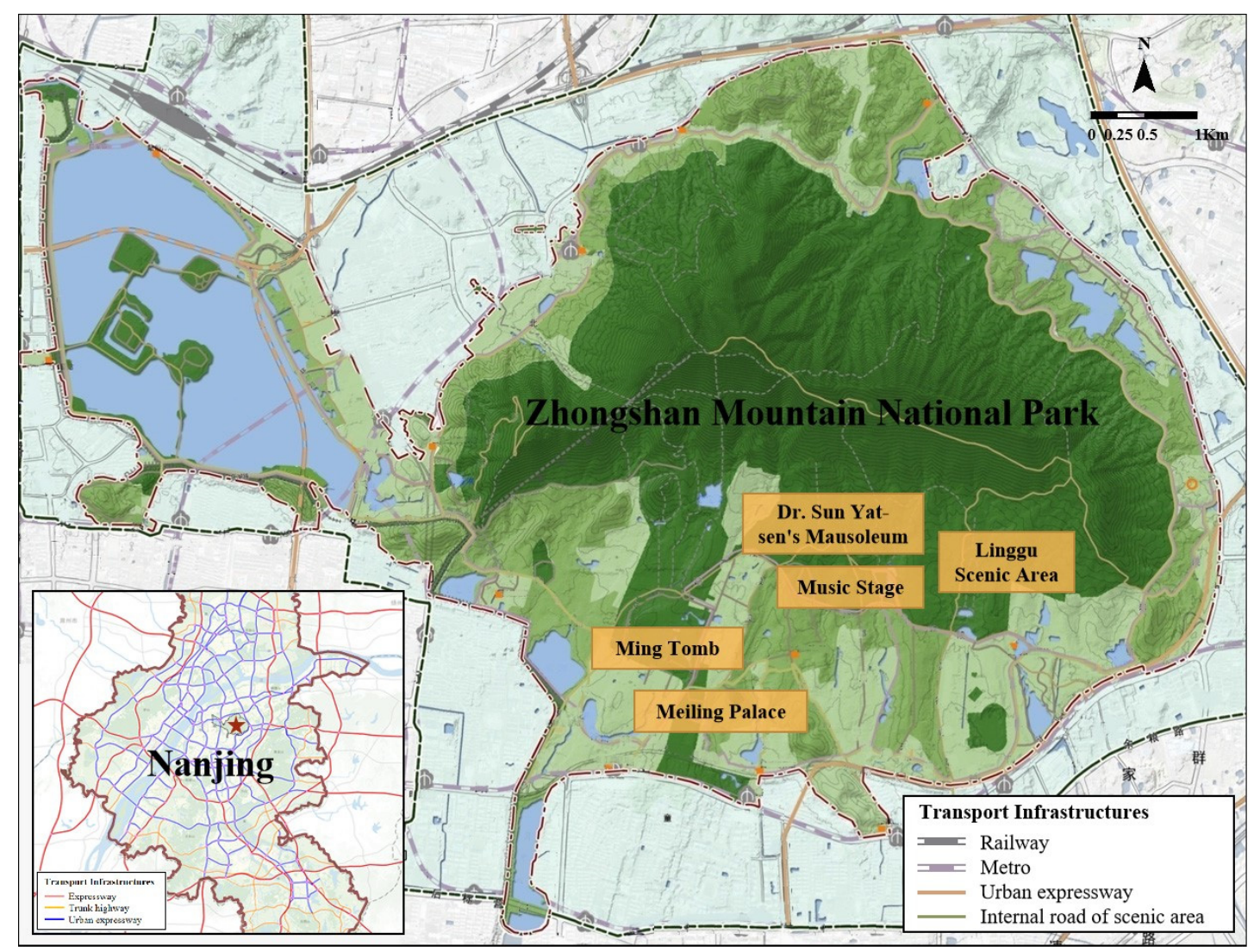

Figure 1. Study area: the Zhongshan Mountain National Park.

\subsection{Descriptive Statistics}

Table 1 shows the statistical details of trip chain patterns and travel modes. Regarding the destination transportation modes, it can be seen that the dominant travel mode was public transport, accounting for $80.7 \%$ of travel. At the same time, tourists preferred public transport in all types of trip chains. The reason could be that traffic congestion during holiday periods encourages tourists to avoid choosing private cars, and the convenience of the metro system contributes to the increased percentage of tourists choosing public transport. When evaluating the trip chain patterns, the statistics showed that tourist travel had a stronger dependency on tour-related activities than on non-tour-related activities, with $88.7 \%$ of tour-related activities compared to $11.3 \%$ of non-tour-related activities. In addition, over three quarters of trip chains were complex trip chains, whereas only one quarter were simple. This result is consistent with the perception that tourists may have planned more than one activity in one day during the holiday, as access to popular travel information services ensures that tourists arrange their plans more efficiently [9]. 
Table 1. Statistics of trip chains and travel modes for weekday tours.

\begin{tabular}{ccccccc}
\hline \multirow{2}{*}{ Transportation Mode } & \multicolumn{5}{c}{ Trip Chain } & \multirow{2}{*}{ Total } \\
\cline { 2 - 5 } & HTH & HOH & HTTH & HOOH & HTOH & \\
\hline Public Transport & $14.4 \%$ & $3.7 \%$ & $41.9 \%$ & $5.2 \%$ & $15.6 \%$ & $80.7 \%$ \\
Private Car & $5.5 \%$ & $0.6 \%$ & $7.3 \%$ & $1.8 \%$ & $4.0 \%$ & $19.3 \%$ \\
Total & $19.9 \%$ & $4.3 \%$ & $49.2 \%$ & $7.0 \%$ & $19.6 \%$ & $100.0 \%$ \\
\hline
\end{tabular}

The independent variables are summarised in Table 2. It can be seen that $51.7 \%$ of the respondents were native tourists and $48.3 \%$ came from other cities and provinces. Approximately $50 \%$ of the tourists in the sample were students, representing the increasing number of college students in China who prefer to travel during holidays. While $63.6 \%$ of the respondents owned a driver's licence and more than $90 \%$ of the respondents had private cars, the percentage of respondents choosing to use private cars was only $19.3 \%$. In terms of the trip attributes, more than half of the respondents travelled with two companions and $52.6 \%$ of respondents only travelled for one day, implying that tourists arrived in the morning and left at night. Furthermore, tourists travelled mainly between 10 and $30 \mathrm{~km}$ to reach their main destinations; typical travel times lasted between 1 and $2 \mathrm{~h}$, whereas travel costs varied from 10 to $30 \mathrm{CNY}$. The two most commonly occurring transfer times are one and two times.

Table 2. Descriptive statistics for the independent variables.

\begin{tabular}{|c|c|c|c|}
\hline Independent Variables & Percentage & Independent Variables & Percentage \\
\hline \multicolumn{2}{|c|}{ Tourists Attribute } & \multicolumn{2}{|c|}{ Transfer Times } \\
\hline Native tourist & $51.7 \%$ & 1 time & $32.4 \%$ \\
\hline Non-local tourists & $48.3 \%$ & 2 times & $32.4 \%$ \\
\hline \multicolumn{2}{|c|}{ Occupation } & 3 times & $24.2 \%$ \\
\hline Students & $46.8 \%$ & $>3$ times & $11.0 \%$ \\
\hline Others & $53.2 \%$ & \multicolumn{2}{|c|}{ Travel Time } \\
\hline \multicolumn{2}{|c|}{ Licence Ownership } & $<30 \min$ & $4.0 \%$ \\
\hline Driving licence & $63.6 \%$ & $30 \mathrm{~min}-1 \mathrm{~h}$ & $26.3 \%$ \\
\hline No driving licence & $36.4 \%$ & $1-2 \mathrm{~h}$ & $41.6 \%$ \\
\hline \multicolumn{2}{|c|}{ Car Ownership } & $2-3 \mathrm{~h}$ & $19.0 \%$ \\
\hline 1 car & $26.3 \%$ & $>3 \mathrm{~h}$ & $9.2 \%$ \\
\hline 2 cars & $57.5 \%$ & \multicolumn{2}{|c|}{ Travel Distance } \\
\hline$>2$ cars & $14.4 \%$ & $<5 \mathrm{~km}$ & $4.9 \%$ \\
\hline no car & $1.8 \%$ & $5-10 \mathrm{~km}$ & $19.3 \%$ \\
\hline \multicolumn{2}{|c|}{ Travel Companies } & $10-30 \mathrm{~km}$ & $41.6 \%$ \\
\hline alone & $2.4 \%$ & $30-50 \mathrm{~km}$ & $17.1 \%$ \\
\hline 1 companion & $7.6 \%$ & $50-100 \mathrm{~km}$ & $12.8 \%$ \\
\hline 2 companions & $56.6 \%$ & $>100 \mathrm{~km}$ & $4.3 \%$ \\
\hline$>2$ companions & $33.3 \%$ & \multicolumn{2}{|c|}{ Travel Cost } \\
\hline \multicolumn{2}{|c|}{ Travel Day length } & $<10(\mathrm{CNY})$ & $18.3 \%$ \\
\hline 1 day & $52.6 \%$ & 10-30 (CNY) & $41.6 \%$ \\
\hline 2 days & $19.0 \%$ & 30-50 (CNY) & $14.7 \%$ \\
\hline 3 days & $11.0 \%$ & 50-100 (CNY) & $12.5 \%$ \\
\hline$>3$ days & $17.4 \%$ & >100 (CNY) & $12.8 \%$ \\
\hline
\end{tabular}




\section{Methodology}

In this study, the NL model was used to explore the relationship between the destination transportation modes and trip chain choices. The NL model has been widely used in transportation studies, which provides a valuable tool to estimate decision makers' choices between different transportation options or travel destinations. Based on the decomposition of the formula in the NL model, the conditional and marginal probabilities ensure that the ratio of the probabilities for any two alternatives in different nests depends on the attributes of the other alternatives. In this manner, the irrelevant alternative (IIA) property does not generally hold for alternatives in different nests, and the NL model can determine the decision order more intuitively. Compared to the MNL and mixed logit models, the NL model showed a better fit with the data used in this study. This was because the MNL model could cause biased estimations from the IIA property, implying that the relative choice probabilities of any two alternatives were not influenced by other alternatives being added or removed from the choice set. Moreover, as the individual traveller tastes were not evaluated in this study, the mixed logit model was not suitable [31].

\subsection{Model Structure}

Two nesting structures were considered to explore tourist travel behaviour, as shown in Figures 2 and 3. The first one has the trip chain patterns above the travel modes, and the second one has the travel modes above the trip chain patterns.

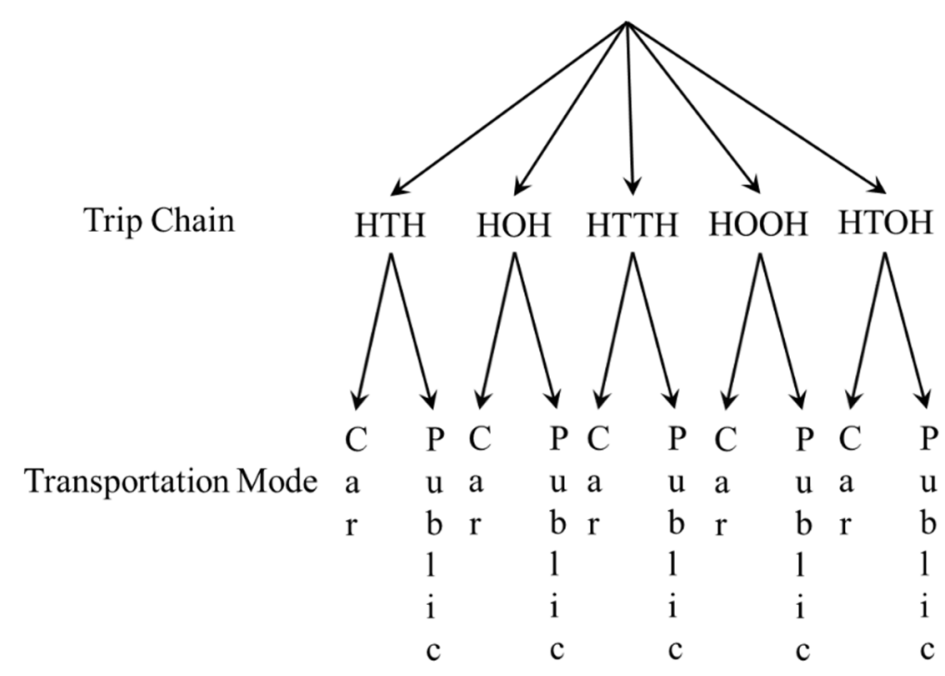

Figure 2. Structure with trip chains above transportation modes.

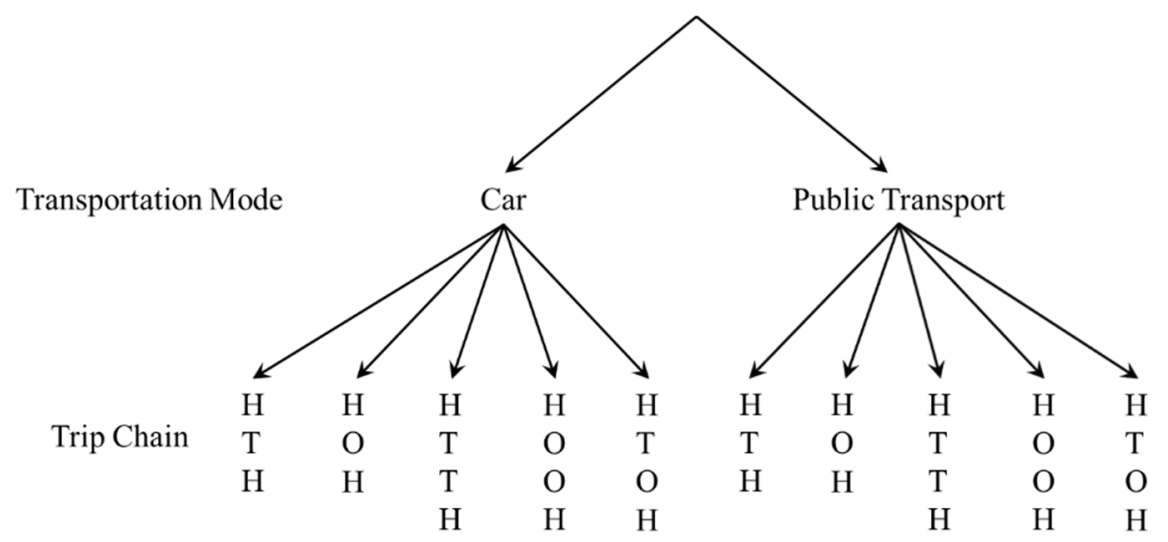

Figure 3. Structure with transportation modes above trip chains. 
According to probability theory, an alternative within nest $B_{k}$ is chosen, and the probability that alternative $i$ is chosen given that an alternative in $B_{k}$ is chosen can be expressed as follows:

$$
P_{n i}=P_{n i \mid B_{k}} P_{n B_{k}}
$$

The marginal and conditional probabilities can be expressed as follows:

$$
\begin{aligned}
& P_{n B_{k}}=\frac{e^{W_{n k}+\lambda_{k} I_{n k}}}{\sum_{l=1}^{K} e^{W_{n l}+\lambda_{k} I_{n l}}}, \\
& P_{n i \mid B_{k}}=\frac{e^{Y_{n i} / \lambda_{k}}}{\sum_{j \epsilon B_{k}} e^{Y_{n j} / \lambda_{k}}},
\end{aligned}
$$

where $I_{n k}$ is called the inclusive value.

$$
I_{n k}=\ln \sum_{j \in B_{k}} e^{Y_{n j} / \lambda_{k}}
$$

Coefficient $\lambda_{k}$ reflects the degree of independence among the unobserved portions of utility for alternatives in nest $B_{k}$, with a lower $\lambda_{k}$ indicating less independence (more correlation). Parameter $\lambda_{k}$ can differ over nests, reflecting different correlations among unobserved factors within each nest. When $\lambda_{k}=1$ for all $k$, indicating no correlation among the unobserved components of utility for alternatives within a nest, the choice probabilities become standard logit [32].

The likelihood ratio index is often used with discrete choice models to measure how well the models fit the data. More precisely, the statistical measures indicate how well a model, with its estimated parameters, performs compared to another model in which all the parameters are zero. The model with a higher $\rho^{2}$ value is more suitable owing to better statistical performance. Following such rules, the structures of the destination transportation mode and trip chain choices can be analysed and explained.

\subsection{Utility Function}

In discrete choice models, decision maker $n$ facing a choice among $J$ alternatives obtains a certain level of utility $U_{n i}$ from choice set $C$. The choice probability is $P_{n i}=\operatorname{Prob}\left(U_{n i}>U_{n j} \forall j \neq i\right)=$ $\operatorname{Prob}\left(U_{n i}-U_{n j}>0 \forall j \neq i\right)$, which means that the decision maker will select the alternative with the largest utility among the choice sets.

The component of utility can be decomposed into three parts: (1) a part labelled $W$ that is constant for all alternatives within a nest, (2) a part labeled $Y$ that varies over alternatives within a nest, and (3) a random component $\varepsilon$. The utility is defined as follows:

$$
U_{n i}=W_{n k}+Y_{n i}+\varepsilon_{n i}
$$

It is often reasonable to express the observed part of the utility using linear parameters:

$$
\begin{gathered}
W_{n k}=\sum_{l=1}^{L} \alpha_{l} x_{n k l}, \\
Y_{n i}=\sum_{m=1}^{M} \beta_{m} z_{n i m},
\end{gathered}
$$

where $x_{n k l}$ is a vector of variables that relate to alternatives for nest $k$, as faced by decision maker $n$; $z_{n i m}$ is a vector of variables that relate to alternative $i ; \alpha_{l}$ and $\beta_{m}$ are the coefficients of the variables, which are the unknown parameters to be estimated. 


\subsection{Explanatory Variables}

In this study, the explanatory variables were classified into three types of determinants: sociodemographic variables, trip-related variables, and travel variables. Among the sociodemographic variables, the occupation, nationality, car ownership, and driving licence ownership influenced the destination mode and trip chain choices $[9,27,28]$. The trip-related variables showed that a higher number of travel companions could make tourists choose a private car over public transport as well as a simple trip chain. The length of stay contributed toward a high probability of choosing public transport and a simple trip chain [17]. Regarding travel variables, it could not determine whether more time- and cost-efficient transportation modes and trip chains were likely to be selected if those choices were available. Furthermore, an increase in travel distance could increase the probability of a person travelling by car and choosing a complex trip chain [8]. The transfer time was also an important factor influencing the choices of tourists, with few studies accounting for it.

The $t$ test was selected to verify whether the coefficient of each explanatory variable was significantly different from zero. The null hypothesis was when the explanatory variable was equal to zero, and test statistics were calculated at $1 \%, 5 \%$, and $10 \%$ confidence intervals, separately. Based on the above discussion, native tourists, occupation, car ownership, and driver's licence ownership were the sociodemographic variables utilised in this study. The trip-related attributes used were the length of stay in days and number of travel companions, whereas the travel variables included the time, cost, distance, and number of transfers.

\section{Results}

Tables 3 and 4 show the estimation results obtained from two NL models. Most of the estimated parameters of the independent variables were statistically significant at confidence levels higher than $95 \%$. Moreover, model 1 had a much larger $\rho^{2}$ value of 0.846 than that of model 2 (i.e., 0.0500 ). Therefore, model 2 was less presentable. Model 1 was effective and exhibited high goodness of fit, suggesting that respondents preferred to decide on their trip chain prior to selecting their travel mode. 
Table 3. Estimation results obtained from model 1.

\begin{tabular}{|c|c|c|c|c|c|c|c|c|c|c|}
\hline & HTH & $\mathrm{HOH}$ & HTTH & HOOH & НТОН & HTH-BUS & HOH-BUS & HTTH-BUS & HOOH-BUS & HTOH-BUS \\
\hline \multicolumn{11}{|c|}{ Constant Term } \\
\hline$X$ & - & - & - & - & - & 1.1607 & $-4.1054^{* * *}$ & $3.6870^{* * *}$ & 2.2747 & 2.9010 \\
\hline Y & - & - & - & - & $-4.2091 * * *$ & - & - & - & - & - \\
\hline \multicolumn{11}{|c|}{ Explanatory Variables for Trip Chain Choice } \\
\hline Time & -0.2643 & -0.2265 & $0.6938^{* * *}$ & -0.0440 & - & - & - & - & - & - \\
\hline Cost & 0.4463 & -0.7645 & $0.3264 *$ & $-1.3169^{* * *}$ & - & - & - & - & - & - \\
\hline Distance & -0.1398 & $-1.3229^{* * *}$ & $-0.8283^{* * *}$ & -0.3066 & - & - & - & - & - & - \\
\hline Transfer & $-0.7721^{* * *}$ & $-1.1999 * * *$ & $-0.4082 * * *$ & $-0.6938^{* * *}$ & - & - & - & - & - & - \\
\hline \multicolumn{11}{|c|}{ Explanatory Variables for Mode Choice } \\
\hline Native & - & - & - & - & - & $-2.4662^{* * *}$ & $5.2901^{* * *}$ & $-1.0124^{* *}$ & $19.4952 * * *$ & $-2.2752 *$ \\
\hline Occupation & - & - & - & - & - & $5.6928 * * *$ & $285.4050^{* * *}$ & $25.5862 * * *$ & 13.6307 & $55.4410^{* * *}$ \\
\hline Licence & - & - & - & - & - & $1.8054^{* * *}$ & $-37.6769^{* * *}$ & $5.8608^{* * *}$ & -3.6370 & $6.5521 * * *$ \\
\hline Car & - & - & - & - & - & -0.5459 & $-2.1405^{* * *}$ & $-1.0364^{* * *}$ & $-4.3685^{* * *}$ & $-4.6962^{* * *}$ \\
\hline Companions & - & - & - & - & - & $1.2178^{* * *}$ & $-32.8571^{* * *}$ & $0.6454^{* *}$ & 0.7522 & - \\
\hline Day Length & - & - & - & - & - & $0.7828^{* * *}$ & $-3.0537^{* * *}$ & -0.3234 & $4.2474^{* * *}$ & $1.4186^{* * *}$ \\
\hline \multicolumn{11}{|c|}{ Inclusive Value Parameters } \\
\hline $\begin{array}{c}\text { Inclusive } \\
\text { Value }\end{array}$ & $-0.3015^{* * *}$ & $-0.1442^{* * *}$ & $0.0530^{* *}$ & $0.1146^{* * *}$ & $0.0597^{* * *}$ & - & - & - & - & \\
\hline$\lambda_{k}$ & $0.0944^{* * *}$ & $0.5515^{* * *}$ & $0.0220 * *$ & $0.0350 * * *$ & $0.0114^{* * *}$ & - & - & - & - & \\
\hline
\end{tabular}


Table 4. Estimation results obtained from model 2.

\begin{tabular}{|c|c|c|c|c|c|c|c|c|c|c|}
\hline & BUS & CAR & BUS-HTH & BUS-HOH & BUS-HTTH & BUS-HOOH & CAR-HTH & CAR-HOH & CAR-HTTH & CAR-HOOH \\
\hline \multicolumn{11}{|c|}{ Constant Term } \\
\hline$x$ & - & - & -0.1525 & - & - & - & -1.4465 & - & - & - \\
\hline $\mathrm{Y}$ & - & $-4.3635^{* * *}$ & - & - & - & - & - & - & - & - \\
\hline \multicolumn{11}{|c|}{ Explanatory Variables for Mode Choice } \\
\hline Time & $0.7872 * * *$ & - & - & - & - & - & - & - & - & - \\
\hline Cost & $-0.5905^{* * *}$ & - & - & - & - & - & - & - & - & - \\
\hline Distance & -0.0599 & - & - & - & - & - & - & - & - & - \\
\hline Transfer & $-0.6832 * * *$ & - & - & - & - & - & - & - & - & - \\
\hline \multicolumn{11}{|c|}{ Explanatory Variables for Trip Chain Choice } \\
\hline Native & - & - & $1.9809^{* * *}$ & $1.4964^{* *}$ & $4.4955^{* * *}$ & $1.0337 * *$ & $2.2624 * * *$ & 2.6518 & 0.4265 & -1.2800 \\
\hline Occupation & - & - & $0.5463 \mathrm{D} 8 * * *$ & $-0.2770 \mathrm{D} 7 * * *$ & $-0.6488 \mathrm{D} 88^{* * *}$ & $0.1326 \mathrm{D} 8 * * *$ & - & - & - & - \\
\hline Licence & - & - & $-2.6287 * * *$ & $-4.0151^{* * *}$ & $-6.5710^{* * *}$ & $-1.3413^{* * *}$ & $-2.0750^{* * *}$ & -0.5081 & 0.8759 & -1.4465 \\
\hline Car & - & - & $1.2632^{* * *}$ & $1.7051 * *$ & $4.6029^{* * *}$ & 0.1801 & 0.6665 & 1.1630 & 0.5295 & $1.4238 *$ \\
\hline Companions & - & - & $-0.9747^{* * *}$ & -0.5968 & $-3.0084^{* * *}$ & $-0.8960^{* * *}$ & -0.2570 & $-1.3439 *$ & -0.5780 & -0.7767 \\
\hline Day Length & - & - & $0.6545^{* * *}$ & -0.1363 & $5.4239 * * *$ & 0.0808 & $-0.7228 * *$ & -1.8871 & -0.1758 & -0.1280 \\
\hline \multicolumn{11}{|c|}{ Inclusive Value Parameters } \\
\hline $\begin{array}{l}\text { Inclusive } \\
\text { Value }\end{array}$ & $0.1726^{* * *}$ & $0.9959 * * *$ & - & - & - & - & - & - & - & \\
\hline$\lambda_{k}$ & $0.0051^{* * *}$ & $0.4598^{* * *}$ & - & - & - & - & - & - & - & \\
\hline
\end{tabular}




\subsection{Inclusive Value Parameters}

The estimated values of $\lambda_{k}$ in model 1 varied from 0 to 1 , which were statistically different from 1 at a confidence level above $95 \%$, indicating that the model was consistent with utility maximization for all possible values of the explanatory variables. These results confirmed that the NL model applied to model 1 , where a low $\lambda_{k}$ indicated higher correlations between transportation mode choices under the same nest. The following paragraphs discuss the estimation results obtained using model 1 .

The inclusive value explains the influence of the mode choice behaviour at the lower level on the trip chain choice at the upper level. The larger estimated inclusive value parameters for the trip chain choice suggested that the respondents' trip chain choices were influenced more strongly by the transportation mode choice. The positive sign of the inclusive value reveals that additional choices of transportation could decrease the probability of choosing a specific trip chain, while the negative sign had the opposite influence. The parameter values of simple trip chains $\mathrm{HTH}$ and $\mathrm{HOH}$ were -0.3015 and -0.14419 , respectively, indicating that a choice set comprising more transportation modes would reduce the probability of respondents choosing a simple trip chain. The absolute value of the inclusive value suggests that the transportation mode choice would influence the choice of trip chain HTH more than that of trip chain $\mathrm{HOH}$. The inclusive values of trip chains $\mathrm{HTTH}, \mathrm{HOOH}$, and $\mathrm{HTOH}$ were all positive. Therefore, various choices in terms of the transportation modes under a trip chain nest could dramatically increase the probability of respondents choosing a specific trip chain. Similarly, a small inclusive value suggests that the choices of HTTH and HTO were less influenced by transportation mode choices.

\subsection{Influential Factors}

The influences of the explanatory variables are discussed below.

Trip Chain Choices: When analysing the influences of trip chain choices, a base alternative must be selected; hence, the trip chain $\mathrm{HTOH}$ was chosen as the base alternative. The travel distance and transfer times were all negative and statistically significant at a 95\% confidence level, i.e., -1.3229 , -0.8283 , and -0.7721 . The reasons for the negative values may be that greater travel distances and transfer times can cause respondents to arrange more activities in a one-day tour, thus prompting them to select trip chain HTOH. The positive parameter value, 0.6938 , of the travel time under trip chain HTTH implies that individuals spending more time travelling to visit more sites might spend a considerable amount of time using transportation. Thus, when comparing the parameter values of the travel cost, it can be seen that only values estimated for a complex trip chain showed significance at the $95 \%$ confidence level, namely 0.3264 and -1.3169 . Hence, individuals spending more are more likely to travel choosing trip chain HTTH and less likely to travel choosing trip chain $\mathrm{HOOH}$; therefore, respondents find high transportation costs acceptable for visiting more tourist destinations than non-tourist ones.

Transportation Mode Choices: To estimate the parameter values of the explanatory variables, the private car was selected as the base alternative. The results showed that non-local respondents positively influenced public transport choices under trip chains HTH and HTTH. This is intuitive, because most non-local respondents travel to Nanjing through high-speed railways and flights, and public transport is suitable for tour activities. The parameters estimated for occupation (5.6928, 285.41, 25.586, and 55.4410) indicated that students were more likely to choose public transport because it is economical. All the parameter values for licence ownership were positive (1.8054 and $5.8608)$ in trip chains including tour activities and negative (-37.677) in trip chains including non-tour activities, as drivers realised the difficulty in finding parking spots around the sites visited. Therefore, respondents selected public transport for tour activities and drove private cars to meet friends or for other commercial activities. In addition, it can be seen that the higher the number of travel companions and travel days, the higher the probability of respondents selecting public transport for tour activities and private transport for non-tour activities. 


\section{Discussion}

\subsection{Relationship between Transportation Modes and Trip Chains}

The structure with trip chains above transportation modes proved effective in describing the sequence used by tourists to decide their trip chains and transportation modes. The result, where the value of $\rho^{2}$ was 0.8486 , was consistent with that obtained in previous research, and the goodness of fit was considerably better than that achieved in other studies, where the $\rho^{2}$ value was usually $0.3-0.4$. Zhao [9] also developed an NL model for analysing travel behaviour on holidays that explored the interrelationships between trip chains and travel mode choices; this model revealed the credibility of the structure with the trip chain above the transportation mode in evaluating travel behaviour during holiday periods. Furthermore, this model fits better with the collected data than the MNL and NL models, where the departure time was selected as the nest [14]. However, the findings may differ from those of Yang et al. [3] in that the structure of the NL model used for analysing travel behaviour on holidays was the opposite of that used in this study. The structure with the transportation mode above the trip chain model fit their research data better. This could be because they analysed the travel behaviour of native tourists, and the data were collected during holidays in 2007; during this period, the tourism industry in China had developed considerably and the travel behaviour of people varied greatly. However, the current study focused on tourist travel behaviour on holidays, considering native and non-local tourists. The findings of this study can be used to reveal how the explanatory variables influence travel decisions.

\subsection{Explanatory Variables for Trip Chain Choices}

In this study, travel time showed a positive effect on the choice of trip chain HTTH, agreeing with previous findings indicating that the length of the trip chain increased with the travel time [2]. In contrast to the findings of other travel behaviour studies, the positive influence of travel time was related to the simple trip chain choices of tourists, probably because there were very few explanatory variables that influenced the estimation results. Wang et al. [29] stated that tourists spending more money on travelling would more likely select trip chains similar to HTTH and HTOH. In this research, further examination of the travel cost showed that this variable had a significant influence on the trip chain choices for tour and non-tour activities, which could be a useful extension of previous research. The effect of travel distance was thoroughly analysed in previous studies [3] and is again highlighted here. Tourists who selected complex trip chains were those who travelled long distances in one day. By contrast, simple trip chains would meet the requirements of tourists not travelling far. Interestingly, this study also revealed that transfer times were significant in terms of trip chain selections.

\subsection{Explanatory Variables Influencing Transportation Mode Choices}

The findings regarding the factors influencing the transportation modes chosen by the tourists indicated similarities and differences with respect to the observations of previous studies. The result that transportation mode choices were influenced by occupation showed high consistency with previous research results. Nutsugbodo and Sven $[23,28]$ also confirmed that students were more likely to select public transport. The findings regarding the influence of driver's licence ownership in this study agreed with those of Wang et al. [29]; tourists owning a driver's licence were more likely to use private cars. In this study, this situation was analysed by considering two aspects: car licence ownership could prompt the use of private cars for non-tour activities and decrease the usage of private cars for tour activities. Positive effects were observed when analysing licence ownership and the decisions of tourists to use private cars; these effects could be understood intuitively, with several researchers proving the credibility of these observations $[3,14,22,28,29]$. By contrast, the number of travel companions had the opposite influence on the probability of choosing specific transportation modes in different trip chains. The higher the number of individuals performing tour activities, the higher the probability of selecting public transport, which is consistent with other research findings [10]. However, private car usage 
increased for non-tour activities, which was also observed in other studies [3,15,27]. Additionally, the day length did not have a significant influence on the transportation mode choices, as observed in previous studies $[10,11,20,27,28]$. One reason could be that the above studies were performed in different countries, and the day length might be a crucial factor in determining the travel behaviour of tourists in China.

\section{Conclusions}

To evaluate the rapid growth of the tourism market in China, a tourist behaviour model needed to be built to explicitly analyse tourist behaviours. Therefore, this study examined the differences and interplay between the choices of trip chains and transportation modes. The data were collected from face-to-face interviews conducted in Nanjing, China, in 2020. The relationship between the two components was analysed by establishing the NL model with two different structures. The results clarified the influence of sociodemographic variables, trip-related variables, and travel variables based on these two aspects.

There were three main findings in this study. Firstly, the decision structure was confirmed to be the trip chain above the transportation mode, which means that tourists preferred to determine the trip chain prior to deciding on the transportation mode. Secondly, the travel variables may have opposing influences on the choice of trip chains, where the tourists may endure more time cost under tour activities than non-tour activities. Thirdly, the choice of transportation mode also varied between tour activities and non-tour activities. For example, when non-local tourists decided to engage in tour activities during the holidays, public transport was more favourable than a private car.

The results of this study have important policy implications for the sustainability of the tourism and transportation sectors. A significant finding of this study is that the explanatory variables have opposing influences on the choices of the different attributes in trip chains, providing valuable opportunities to implement specific policies aimed at different tourist groups. The results indicated that higher times and costs are acceptable when tourists select trip chains with complex tour activities, such as HTTH. Therefore, it is necessary to improve public transportation facilities and attract more people to take sustainable transportation to ensure relaxed and comfortable travel, especially for complex tourism activities. Tourists choosing HTH, HTTH, or HTOH prefer public transport when they have many travel companions and the day length is long. Therefore, public transport service managers should cater to tourist requirements, such as providing more specialist tour bus routes connecting various famous sites. Such initiatives also help to simplify travel activity and enhance the flow of people between scenic spots, so that tourism and transportation can develop together sustainably. For holiday tours, students prefer public transport, and public transport discount policies aimed at students may be helpful. In addition, travellers with driver's licences are more likely to use private cars. Accordingly, cost-based traffic management strategies such as introducing toll lanes, congestion pricing, and charging for time-sharing parking around scenic spots can be expected to work effectively during holiday periods.

There are nevertheless two potentially important limitations in the present study. The first is that the transportation mode choice only consisted of private cars and public transportation, whereas more travel mode choices, such as subways, taxis, and online ride-hailing services should be considered in order to more accurately reflect the real-world situation. The second limitation concerns the fact that the data of this research were collected in one year, while it was necessary to use panel data to verify the existing findings.

This study is an initial step in examining the relationship between the trip chain and transportation mode choices for evaluating the travel behaviour of tourists on holidays. However, further comprehensive research is necessary. Firstly, the choices of tourists might be influenced by variations in their tastes or preferences. Consequently, variations may occur in parameter estimation, so it would be necessary to adopt more complex models, such as the mixed logit model. Furthermore, simulations for analysing the changes in tourist travel behaviour should be performed to predict the 
influence of transportation systems and socioeconomic factors and explore different management policies that could effectively support the rapid growth of tourism in China during holiday periods.

Author Contributions: Conceptualization, C.Q.; methodology, C.Q.; software, C.Q.; validation, Z.Z., R.L. and J.C.; formal analysis, C.Q.; investigation, X.G.; resources, X.G.; data curation, Z.Z.; writing-original draft preparation, C.Q.; writing-review and editing, Z.Z.; visualization, R.L.; supervision, J.C.; project administration, C.Q.; funding acquisition, Z.Z. All authors have read and agreed to the published version of the manuscript.

Funding: This research was funded by the Scientific Research Foundation for Advanced Talents of Nanjing Forestry University, grant number 163106041.

Acknowledgments: Guo and Teachers of Southeast University are appreciated for providing helpful suggestions on this research. The anonymous referees whose comments on the earlier version led to significant improvements should also be appreciated.

Conflicts of Interest: The authors declare no conflict of interest.

\section{References}

1. China Statistical Yearbook. 2019. Available online: http://www.stats.gov.cn/tjsj/ndsj/2019/indexch.htm (accessed on 11 September 2020).

2. Wang, B.; Shao, C.; Li, J. Holiday travel behavior analysis and empirical study under integrated multimodal travel information service. J. Transp. Syst. Eng. Inf. Technol. 2015, 39, 21-36. [CrossRef]

3. Yang, L.; Shen, Q.; Li, Z. Comparing travel mode and trip chain choices between holidays and weekdays. Transp. Res. 2016, 91, 273-285. [CrossRef]

4. Schneider, F.; Ton, D.; Zomer, L.B. Trip chain complexity: A comparison among latent classes of daily mobility patterns. Transportation 2020, 1-23. [CrossRef]

5. Cheng, L.; Chen, X.; Yang, S. An exploration of the relationships between socioeconomics, land use and daily trip chain pattern among low-income residents. Transp. Plan. Technol. 2016, 39, 358-369. [CrossRef]

6. Wan, Q.; Li, Z.; Qi, Y. Comparing uncertainties in travel mode choice decisions for various trip chains. Adv. Mech. Eng. 2019, 11. [CrossRef]

7. Hadiuzzaman, M.; Farazi, N.P.; Hossain, S. Structural equation approach to investigate trip-chaining and mode choice relationships in the context of developing countries. Transp. Plan. Technol. 2019, 42, 391-415. [CrossRef]

8. Putu, H.; Sakti, A.A.; Muhammad, I.R.; Sumarni, H. Choice models of trip chain and transportation mode for international tourists in tourism destination island. Int. J. Geomate 2019, 16, 195-203.

9. Zhao, X. The Research of Tourist Behavior Based on Trip-Chain Doctoral Dissertation; Beijing University of Technology: Beijing, China, 2012.

10. Le, K.; Diem, T. Factors affecting tourists' public transport use and areas visited at destinations. Tour. Geogr. 2015, 17, 738-757.

11. Masiero, L.; Zoltan, J. Tourists intra-destination visits and transport mode: A bivariate probit model. Ann. Tour. Res. 2013, 43, 529-546. [CrossRef]

12. Wu, L.L.; Zhang, J.; Fujiwara, A. Dynamic Analysis of Japanese tourists' three stage choices: Tourism participation, destination choice, and travel mode choice. Transp. Res. Rec. 2012, 2322, 91-101. [CrossRef]

13. Jaume, G.; Catalina, J.; Josep, M.R.; Francesc, S. A Study of Traveller Decision-Making Determinants: Prioritizing Destination or Travel Mode. Tour. Econ. 2015, 21, 1149-1167.

14. Li, G.F.; Long, H.Y. Chengdu Tour Transportation Behavior. J. Transp. Eng. Inf. 2016, 14, 36-41.

15. Park, D.; Lee, G.; Kim, W.G. Social Network Analysis as a Valuable Tool for Understanding Tourists' Multi-Attraction Travel Behavioral Intention to Revisit and Recommend. Sustainability 2019, 11, 2497. [CrossRef]

16. Barros, V.G. Transportation choice and tourists' behavior. Tour. Econ. 2012, 18, 519-531. [CrossRef]

17. Gutiérrez, A.; Daniel, M. The Determinants of Tourist Use of Public Transport at the Destination. Sustainability 2016, 8, 908 .

18. Martin, M.J.M.; Guaita, M.J.M.; Molina, M.V. An Analysis of the Tourist Mobility in the Island of Lanzarote: Car Rental Versus More Sustainable Transportation Alternatives. Sustainability 2019, 11, 739. [CrossRef] 
19. Thrane, C. Examining tourists' long-distance transportation mode choices using a Multinomial Logit regression model. Tour. Manag. Perspect. 2015, 15, 115-121. [CrossRef]

20. Vo, V.C. Estimation of travel mode choice for domestic tourists to Nha Trang using the multinomial probit model. Transp. Res. Part A Policy Pract. 2013, 49, 149-159.

21. Antolin, G.; Alonso, B.; Cordera, R. The Effect of Introducing Parking Policies on Managing Mobility to Beaches in Touristic Coastal Towns. Sustainability 2019, 11, 3528. [CrossRef]

22. Azari, K.A.; Arintono, S.; Hamid, H. Effects of parking and cordon charge policies on tourist's modal shift in central business district of Mashhad city, Iran. Curr. Issues Tour. 2012, 15, 489-496. [CrossRef]

23. Nutsugbodo, R.Y.; Amenumey, E.K.; Mensah, C.A. Public transport mode preferences of international tourists in Ghana: Implications for transport planning. Travel Behav. Soc. 2018, 11, 1-8. [CrossRef]

24. Nakamura, H.; Abe, N. Tourist decisions in renting various personal travel modes: A case study in Kitakyushu City, Japan. Tour. Manag. 2016, 55, 85-93. [CrossRef]

25. Orsi, F.; Geneletti, D. Assessing the effects of access policies on travel mode choices in an Alpine tourist destination. J. Transp. Geogr. 2014, 39, 21-35. [CrossRef]

26. Pettebone, D.; Newman, P.; Lawson, S.R. Estimating visitors' travel mode choices along the Bear Lake Road in Rocky Mountain National Park. J. Transp. Geogr. 2011, 19, 1210-1221. [CrossRef]

27. Aaron, G.; Miravet, D.; Òscar, S. Transport Mode Choice by Tourists Transferring from a Peripheral High-Speed Rail Station to Their Destinations: Empirical Evidence from Costa Daurada. Sustainability 2019, 11, 3200.

28. Sven, G.; Bente, G. Sustainable mode of transport choices at the destination-Public transport at German destinations. Tour. Rev. 2018, 73, 401-420.

29. Wang, B.B. Reconstruction and Evolution Analysis of Holiday Activity Chain under Integrated Multimodal Travel Information Service. Ph.D. Thesis, Beijing Jiaotong University, Beijing, China, 2017.

30. Nanjing Smart Tourism Big Data Operation Monitoring Platform Data Report. Available online: http://wlj.nanjing.gov.cn/njswhgdxwcbj/202006/P020200612355023226717.pdf (accessed on 12 June 2020).

31. Ben-Akiva, M.; Lerman, S.R. Discrete Choice Analysis: Theory and Application to Travel Demand; The MIT Press: London, UK, 1985; pp. 285-291.

32. Kenneth, E.T. Discrete Choice Models with Simulation; The Cambridge University Press: Cambridge, UK, 2002; pp. 81-90.

(C) 2020 by the authors. Licensee MDPI, Basel, Switzerland. This article is an open access article distributed under the terms and conditions of the Creative Commons Attribution (CC BY) license (http://creativecommons.org/licenses/by/4.0/). 